\title{
Effect of Various Rapid Cooling Treatment on the Structural Properties of Iron Nickel Aliminium Alloy Deposited by Detonation-Gun (D-Gun) Method
}

\author{
Masbah R.T. Siregar,* Gerald E. Timuda, ${ }^{\dagger}$ Farid W. Machmud, and Muchiar \\ Research Center for Physics, Indonesian Institue of Science (LIPI), \\ Kawasan PUSPIPTEK Serpong - Tangerang Selatan 15314, Banten - Indonesia
}

\begin{abstract}
Iron base alloy such as iron aluminide (Fe-Al) is known as corrosion resistance material at elevated temperature. Addition of chromium and nickel to the material can increase the temperature capability. Deposition of Fe38Ni10Al alloy material has been done by using D-Gun method on Stainless Steel substrate. One of the characteristics should be evaluated is the crystalline structural properties of the alloy. It is known that nanocrystalline or amorphous structure is preferable as they are able to increase the mechanical properties. Rapid cooling treatment of the alloys from its molten state is done to give different chemical and mechanical properties, to achieve nanocrystalline structure. This treatment was carried out by rotating the substrate and simultaneously rotating and spraying distilled ice-water to the substrate throughout the deposition process. From the XRD pattern of the deposited alloys, there can be seen the occurrence of phase transformation compared to as-received alloy. The $\gamma$-(Fe,Ni), FeNi $i_{3}$ and $\mathrm{Al}$ phase of as-received alloy were changed into only $\gamma$-(Fe,Ni) phase of deposited alloys. The apparent crystal size evaluated by Scherrer Method was in nanometer scale size. The successive spraying of distilled ice-water gives effect on the decrease of crystal size of the deposited alloy (37.78 nm) as compared to non-sprayed deposited alloy $(56.80 \mathrm{~nm})$.
\end{abstract}

KEYwORDS: FeNiAl alloy, Detonation-Gun, Rapid Cooling, XRD, Scherrer Method, Nanocrystalline

\section{INTRODUCTION}

Surface modification technology has drawn wide attention because it gives alternative and cheaper way to increase mechanical properties of material and in the same time affords protection from environmentally degradation [1]. The common method is to apply coating of thin layer of certain substrate on material surface [2]. Thermal and plasma based coating method such as Atmospheric Plasma Spray [1,3], High Velocity Oxygen Fuel (HVOF) [4] and Detonation Gun (DGun) coating [1-3,5], are an alternative method that can give a specific surface property of material [2].

D-Gun coating method is proven as a good method to coat several types of materials such as ceramics $[1,3]$, metal alloy [2,5] carbide [1] and cermets [6] with high mechanical properties. This method has several advantages compared to the plasma spray method and HVOF. It is more effective on the gas consumption, and produces coated material with better mechanical properties (e.g. bigger hardness and better wear resistance, smaller porosity, etc.) [1]. D-Gun coating system can produce detonation wave produced from detonation of the gas fuel with various velocity ranging from $1090 \mathrm{~m} / \mathrm{s}$ (for $\mathrm{CO}_{2}$ and $\mathrm{O}_{2}$ mixture) to $3525 \mathrm{~m} / \mathrm{s}$ (for $\mathrm{H}_{2}$ and $\mathrm{O}_{2}$ mixture). This high energy detonation wave will heat, molten and accelerate particle injected to the detonation chamber with ve-

\footnotetext{
*E-MAIL: masb001@lipi.go.id
}

${ }^{\dagger}$ E-MAIL: gera001@lipi.go.id locity about $600-1200 \mathrm{~m} / \mathrm{s}$ [2]. This accelerated "molten"particle thus became well coated to the surface of the substrate placed in correct distance from the barrel. The high quality of the coating can be achieved by correctly adjusting process parameters, such as fuel ratio, powder carrier gas flow rate, spray distance, firing frequency, rapid cooling treatment, etc.

Rapid cooling treatment was given so the particle posses rapid solidification to achieve enhanced chemical and mechanical structure of material [7]. By giving rapid cooling treatment on the coated material produced by D-Gun, different crystalline structures of coated material were observed compared to as-received powder material before it was coated [2].

This paper presents the experiment of coating material by D-Gun method with different rapid cooling treatment. The different treatment was given to analyze effect of different cooling rate on the crystalline properties of deposited material.

\section{METHODOLOGY}

The material used was as-received $\mathrm{Fe}_{38} \mathrm{Ni} i_{10} \mathrm{Al}$ (Metco Sultzer) powder, without further treatment. The SEM picture of this material was given in Figure 1. Substrate to be coated was Stainless Steel AISE 316. Detonation Gun Coating System used, as shown in Figure 2, was build and operates at Research Center for Physics - Indonesian Institute of Sciences (P2F-LIPI). The D-Gun was operated at specific parameters as shown in Table 1.

Two samples were prepared for two types of rapid cooling 
TABLE I: The operation condition of D-Gun system parameters.

\begin{tabular}{|c|c|c|c|c|c|c|c|}
\hline $\begin{array}{l}\text { Sample } \\
\text { code }\end{array}$ & $\begin{array}{c}\text { Ratio of } \\
\mathrm{C}_{2} \mathrm{H}_{2}: \mathrm{O}_{2}\end{array}$ & $\begin{array}{l}\text { Powder Carrier } \\
\text { Gas Flow (psi) }\end{array}$ & $\begin{array}{c}\text { Spray } \\
\text { distance }(\mathrm{mm})\end{array}$ & $\begin{array}{c}\text { Paramete } \\
\text { Voltage applied } \\
\text { on Rotating } \\
\text { Device }(\mathrm{V})\end{array}$ & $\begin{array}{l}\text { Firs } \\
\text { Fing frequency } \\
(\mathrm{Hz})\end{array}$ & $\begin{array}{l}\text { Detonation } \\
\text { Cycle }\end{array}$ & $\begin{array}{l}\text { Rapid } \\
\text { Cooling } \\
\text { Treatment }\end{array}$ \\
\hline$\overline{\text { IS01 }}$ & $0.6: 2.8$ & 28 & 140 & 220 & 1 & $40 x$ & Rotation only \\
\hline IS05 & $1.05: 2.8$ & 28 & 140 & 220 & 1 & $100 x$ & Rotation and Spraying \\
\hline
\end{tabular}

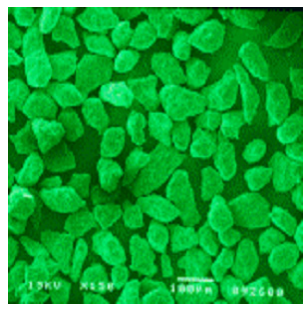

FIG. 1: Typically of SEM photograph of $F e_{38} N i_{10} A l$ powder

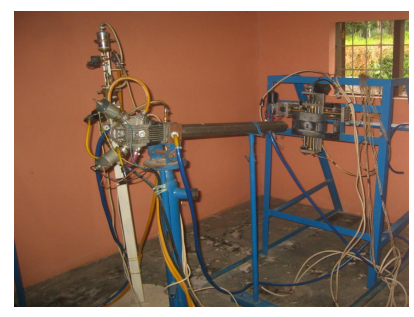

(a)

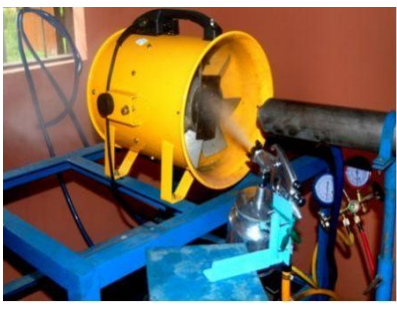

(b)

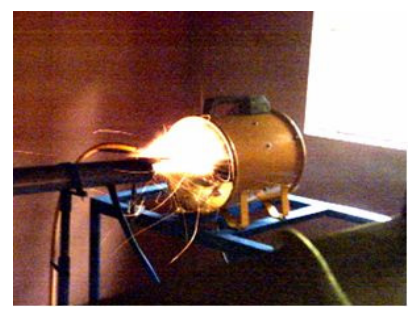

(c)

FIG. 2: Experimental setup of D-Gun system. (left) The D-Gun system at Research Center for Physics, Indonesian Institute of Science. (middle) The rapid cooling device consisted of high speed rotating sample holder and spray gun filled with ice water. (right) The D-Gun system in operation.

treatment (Table 1). The first was IS01, prepared for rapid cooling treatment from rotation only, by rotating the substrate at high rpm. The second sample (IS 05) was given treatment from rotation as for the first sample, followed by spraying ice water $\left( \pm 0^{\circ} \mathrm{C}\right)$ on the substrate each time detonation cycle ended (Figure 2). Also, the amount of acetylene gas for the second sample is set bigger than the first one. Hence, the temperature inside detonation chamber became bigger. These two changes were done to make sure that the cooling rate of the second sample is bigger than the first one. To analyze the crystalline structure, all of the samples were characterized using XRD, and the result was compared to the characteristic of as-received powder.
TABLE II: Analysis of XRD pattern of $F e_{38} N i_{10} A l$ powder.

\begin{tabular}{|c|c|c|c|}
\hline $\begin{array}{l}\text { Peak } \\
(2 \theta \mathrm{deg})\end{array}$ & $\mathrm{I} / \mathrm{I} 0$ & hkl & $\mathrm{Ph}_{2}$ \\
\hline 38.32 & 45 & 111 & $\overline{\mathrm{Al}}$ \\
\hline 43.42 & 69 & 111 & $\gamma-(\mathrm{Fe}-\mathrm{Ni})$ \\
\hline 44.38 & 100 & 111 & $\mathrm{FeNi} i_{3}$ \\
\hline 50.68 & 31 & 200 & $\gamma-(\mathrm{Fe}-\mathrm{Ni})$ \\
\hline 51.7 & 22 & 200 & $\mathrm{FeNi} i_{3}$ \\
\hline 54.98 & 6 & 220 & $\mathrm{Al}$ \\
\hline 74.64 & 23 & 220 & $\gamma-(\mathrm{Fe}-\mathrm{Ni})$ \\
\hline 76.30 & 13 & 220 & $\mathrm{FeNi} i_{3}$ \\
\hline 90.74 & 22 & 311 & $\gamma-(\mathrm{Fe}-\mathrm{Ni})$ \\
\hline 95.80 & 10 & 222 & $\gamma-(\mathrm{Fe}-\mathrm{Ni})$ \\
\hline
\end{tabular}

\section{RESULTS AND DISCUSSIONS}

The XRD pattern of the as-received Fe 38Ni10Al powder is shown in Figure 3. The crystalline structure of this material consisted of several phases (Table 2). The first phase is Al, which is detected at the $2 \theta$-peak of $38.32^{\circ}$ and $64.98^{\circ}$. The second phase is taenite, $\gamma-(\mathrm{Fe}-\mathrm{Ni})$ which is detected at $43.42^{\circ}$, $50.68^{\circ}, 74.64^{\circ}, 90,74^{\circ}$ and $95,80^{\circ}$. The third one is $F e N i_{3}$, detected at $44.38^{\circ}$ and $76.30^{\circ}$.

The XRD pattern of the material after deposition on the substrate is shown in Figure 4. From the pattern of these substrates, it can be seen that there are several peaks which is missing. This indicates that there is difference in the crystalline structural properties of the material. The crystalline structure of the deposited material for both samples is taenite, $\gamma$-(Fe-Ni) only (Table 3$)$. This can be seen on the pattern of the three peaks at 2- $\theta$ angle of $43.440,50.410$ and 74.530 for sample IS01 and 43.440, 50.400 and 74.450 for sample IS05. Apparently, the energy that the particle received inside the chamber during detonation process is high enough to affect the crystalline structure of the material. This result is similar to the previous research already reported [2].

To analyze the crystalline size of the deposited materials, Scherrer Method was used. By using this method one can calculate the apparent crystalline size (ACS) according to:[8]

$$
A C S=\frac{k \lambda}{\beta \cos \theta}
$$

where $\mathrm{k}$ is a constant $(=0,89), \lambda$ is wavelength of the $\mathrm{X}$-Ray used (= $1.542 \AA$ for $\mathrm{Cu}-\mathrm{k} \alpha$ ), and $\beta$ is full width at half maximum (FWHM) of the peak at angle $2 \theta$.

The calculated crystalline size is presented in Table 4. All samples have crystalline size in nanocrystalline scale (less 


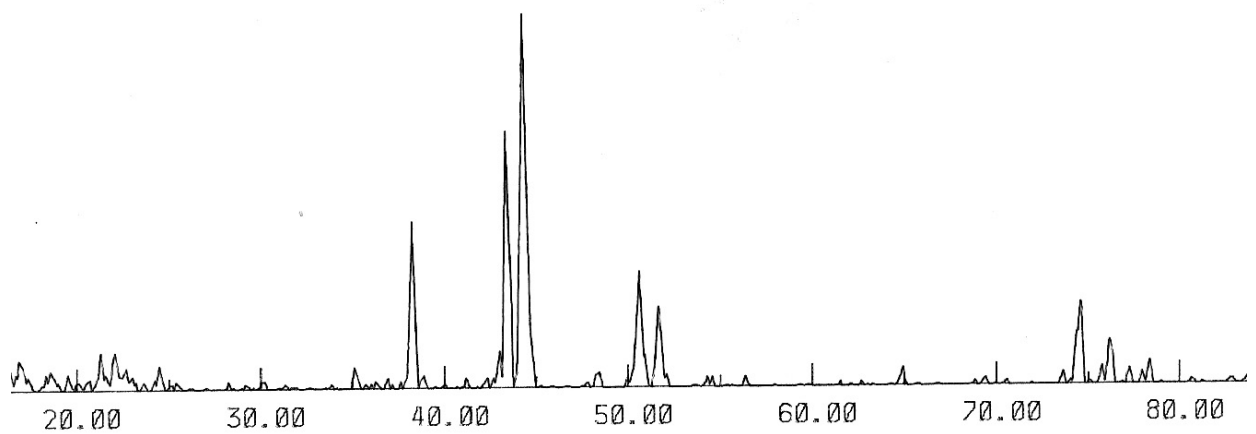

FIG. 3: The XRD Spectrum of $F e_{38} N i_{10} A l$ powder

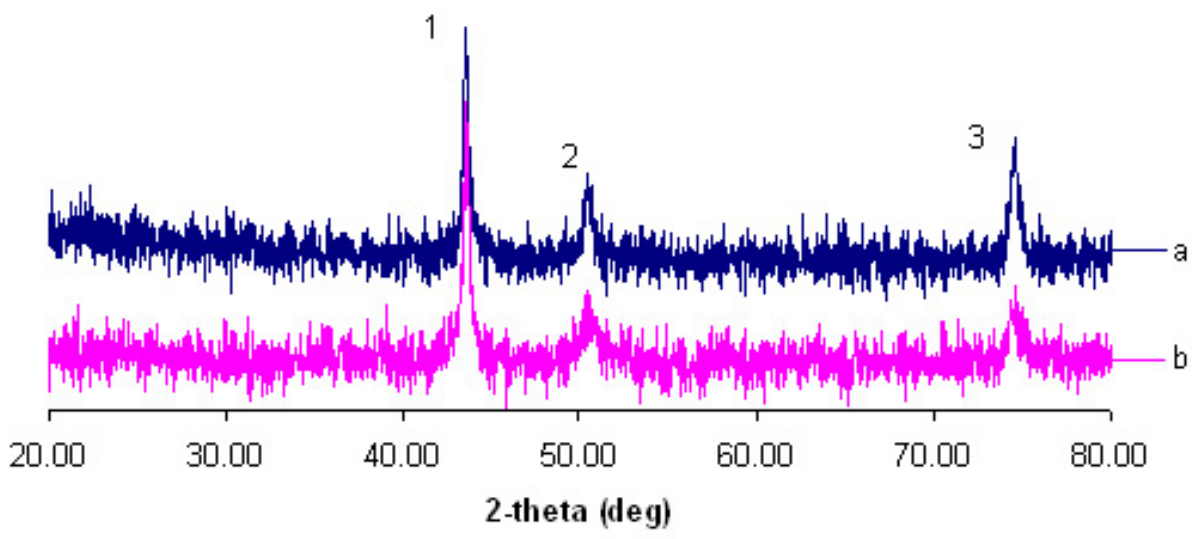

FIG. 4: The typical XRD pattern of FeNiAl alloy deposited by D-Gun using rapid cooling treatment by (a) rotating only (sample SS01) and (b) successfully rotating and spraying ice water to the substrate (sample SS05)

TABLE III: Analysis of XRD pattern of deposited alloy.

\begin{tabular}{|c|c|c|c|}
\hline $\begin{array}{l}\begin{array}{l}\text { Sample } \\
\text { code }\end{array} \\
\text { col }\end{array}$ & $\begin{array}{c}\text { Peak } \\
(2 \theta \mathrm{deg})\end{array}$ & I/I0 hkl & $\overline{\mathrm{Ph}}$ \\
\hline \multirow[t]{3}{*}{$\overline{\text { IS } 01}$} & 43.44 & 100111 & $-(\mathrm{Fe}, \mathrm{Ni})$ \\
\hline & 5 & 34200 & \\
\hline & 74.53 & 56220 & $\gamma-(\mathrm{Fe}, \mathrm{Ni})$ \\
\hline \multirow[t]{3}{*}{ IS 05} & 43.44 & 100111 & $\gamma-(\mathrm{Fe}, \mathrm{Ni})$ \\
\hline & 50.40 & 19200 & $\gamma-(\mathrm{Fe}, \mathrm{Ni})$ \\
\hline & 74.45 & $23 \quad 220$ & $\gamma-(\mathrm{Fe}, \mathrm{Ni})$ \\
\hline
\end{tabular}

than $100 \mathrm{~nm}$ ). The first sample (IS01) has crystalline size of $56.80 \mathrm{~nm}$ and the second sample (IS05) of $37.78 \mathrm{~nm}$. From this result we can see that the second sample has the smaller crystalline size. It means that the sample with bigger cooling rate during detonation process produce smaller crystalline size, as expected.

\section{CONCLUSION}

Detonation Gun (D-Gun) coating method successfully coated FeNiAl material on stainless steel substrate. The crys- talline structure of the coating material $(\mathrm{Al}, \gamma-(\mathrm{Fe}, \mathrm{Ni}), \mathrm{FeNi} 3)$

TABLE IV: Crystalline size of deposited alloy calculated using Scherrer Method.

\begin{tabular}{lccc}
\hline \hline $\begin{array}{l}\text { Sample } \\
\text { code }\end{array}$ & $\begin{array}{c}\text { Peak } \\
(2 \theta \mathrm{deg})\end{array}$ & $\begin{array}{c}\text { Crystalline } \\
\text { Size }(\mathrm{nm})\end{array}$ & $\begin{array}{c}\text { Average } \\
\text { Crystalline Size }(\mathrm{nm})\end{array}$ \\
\hline IS 01 & 43.44 & 59.20 & 56.80 \\
& 50.41 & 70.91 & \\
& 74.53 & 40.31 & \\
IS 05 & 43.44 & 51.80 & 37.78 \\
& 50.40 & 21.27 & \\
& 74.45 & 40.29 & \\
\hline \hline
\end{tabular}

is changed after being coated $(\gamma-(\mathrm{Fe}, \mathrm{Ni})$ only $)$ due to high energy received during detonation process. The different rapid cooling treatments produce different crystalline sizes of coated material. The higher the cooling rate makes the crystalline size smaller. 
[1] G. Sundararajan, K.U.M. Prasad, D.S. Rao, and S.V. Joshi, Journal of Materials Engineering and Performance (JMEPEG), vol. 7(3), pp.343 - 351, June 1998.

[2] F.W. Machmud, M.R.T. Siregar, Cece, Proceeding of ASEANIndia Workshop and Annual Meeting on Surface Engineering (AISE) II, 2009, Indonesia, pp. 79 - 83, ISBN 978-979-858024-6.

[3] P. Saravanan, V. Selvarajan, M.P. Srivastava, D.S. Rao, S.V. Joshi, and G. Sundararajan, Journal of Thermal Spray Technology, Vol. 9 No. 4, pp. 505 - 512, December 2000.

[4] E. Riyanto, B. Prawara, Supriyatno, Proceeding of ASEANIndia Workshop and Annual Meeting on Surface Engineering
(AISE) II, 2009, Indonesia, pp. 72 - 78, ISBN 978-979-858024-6.

[5] F.W. Machmud, M.R.T. Siregar, Muchiar, Proceeding of Applied Science for Technology Innovation (ASTECHNOVA), 2009, Indonesia, Vol.1 No.1 pp.IV-19 - IV-29, ISSN 2086-0005

[6] G.Yang, H. Zu-kun, X.Xiaolei, X.Gang, Journal of Thermal Spray Technology Vol. 10(3), pp456-460, September 2001

[7] T.K. Ibrahim, A.S. Humod, Eng \& Tech, Vol. 25 No. 10, pp. $1102-1109,2007$

[8] H Han, L Zan, J Zhong, L Zhang, X Zhao, Material Science and Engineering B, Vol. 110, pp. 227 - 232, 2004 